\title{
Reversible Deactivation Radical Polymerization Mediated by Nitroxides and Green Chemistry
}

\author{
M. Yu. Zaremski ${ }^{a, *}$, and N. S. Melik-Nubarov ${ }^{a}$ \\ ${ }^{a}$ Faculty of Chemistry, Moscow State University, Moscow, 119991 Russia \\ *e-mail:zaremski@mail.ru \\ Received March 27, 2021; revised May 14, 2021; accepted May 28, 2021
}

\begin{abstract}
This review is the first attempt to consider application of some principles of green chemistry to reversible-deactivation radical polymerization mediated by nitroxides. The results of controlled synthesis of easily degradable polymers and polymers synthesized under conditions of green chemistry by photopolymerization, polymerization in supercritical carbon dioxide, and polymerization of monomers from renewable raw materials are discussed.
\end{abstract}

DOI: $10.1134 / \mathrm{S} 1811238221020120$

\section{INTRODUCTION}

The general concept of green chemistry including 12 principles was first formulated in 1998 by P.T. Anastas and J.C. Warner at American Chemical Society $[1,2]$. Later, this concept was developed and corrected and the sequence of its principles was revisited; however, its main provisions and number remained unchanged [3]. The essence of these principles is as follows.

1. Prevention: it is better to prevent waste than to treat it. The quantitative measure of this principle is the $E$ factor that relates the weight of waste to the weight of the desired product [4-6]. Its value varies in a wide range from 0.1 in oil refining to 100 in pharmaceuticals. As applied to the synthesis of polymers, this criterion first of all implies designing a process so that a monomer can be maximally converted to a polymer [5].

2. Atom economy: synthetic methods should be designed to maximize the incorporation of initial substances into the final product. This principle is characterized by parameter $\mathrm{AE}$ equal to the ratio of molecular weight of a product to the sum of molecular weights of all initial compounds [7]. The second criterion may be treated as a specification of the first principle. It involves the choice of those synthetic methods in which there would be no byproducts in addition to the target product. Thus, from the point of view of green chemistry polymerization is more preferable than polycondensation for the synthesis of polymers, because in the latter a low molecular weight product is usually obtained along with the polymer. For example, for nylon- 6 produced by the ring-opening polymerization of caprolactam parameter AE close to $100 \%$, while for its analog, nylon-6,6, manufactured by polycondensation $\mathrm{AE}=91.3 \%$ [5].
3. Nontoxicity of initial and final substances: synthetic methods should be designed to use and generate substances that are as much as less hazardous to human health and the environment. In polymerization processes, this criterion will only be met by half in most cases. Although the majority of manufactured polymers are harmless to nature and human, monomers used in their synthesis are as a rule toxic.

4. Designing safer chemicals: new chemical products should be designed to effect their desired function while minimizing their toxicity. In this respect, methods of controlled radical polymerization have both pros and cons. On the one hand, just methods of controlled radical polymerization are the powerful tool to produce polymers and especially copolymers of the specified structure, including gradient and multiblock, with desired properties [8-12]. On the other hand, these methods generally use toxic controlling agents. This concerns to the greatest extent atom transfer polymerization which leads to the contamination of products by toxic salts of copper and other heavy metals; to the lowest extent, polymerization mediated by reversible inhibitors, nitroxides.

5. Nontoxic solvents and auxiliary chemicals: in the chemical production, the use of solvents and other auxiliary chemicals should be avoided or they should be nontoxic. As applied to controlled radical polymerization, this implies, first, search for nontoxic controlling agents and, second, implementation of the process in eco-friendly media, among which are not only aqueous solutions but also ionic liquids and various aqueous dispersion media [5].

6. Minimization of energy requirements: chemical synthesis should be conducted at a temperature close to room temperature under atmospheric pressure. In 
the field of controlled radical polymerization, solution to this task is basically aimed at searching for new controlling agents capable of photopolymerization.

It should be emphasized that one of the first of attempts to minimize energy requirements in the polymerization synthesis was made by Soviet theoretical chemists already in the 1970s when a model of continuous reactor operating under self-heating of the reaction mixture driven by heat released in the exothermal polymerization reaction was developed [13].

In fact, energy requirements to maintain the desired temperature of polymerization make up a small part $(<10 \%)$ of energy requirements for the entire manufacturing process [14].

7. The use of renewable feedstocks. Renewable feedstocks are defined as agricultural raw materials and waste products of other industries, as opposed of petroleum, gas, and other natural resources. This area in the synthesis of polymers has only recently begun to be developed although the resource of monomers based on biomass is fairly diverse [15]. The quantitative measure of this criterion is carbon balance $\Delta \mathrm{C}$, a difference between the amount of carbon consumed from air and released back during synthesis and fuel consumption. Rule $\Delta \mathrm{C} \gg 0$ should be fulfilled.

8. Reduction in intermediate stages: the use of intermediate stages, for example, protection and deprotection of reactive groups, should be minimized because extra stages may cause additional pollution of the environment. The successful application of controlled radical polymerization to solve this problem is illustrated in a review [5] with the example of synthesis of poly(2-hydroxyethyl methacrylate). Earlier, for this purpose, a group transfer living anionic polymerization was used [16] which includes two additional stages: protection of the $\mathrm{OH}$ group of a monomer and deprotection when polymerization is completed. Using atom transfer polymerization the same polymer can be synthesized directly from the monomer [17].

9. Catalysis: it is better to use a catalytic amount of substances than the stoichiometric one [18]. The catalytic amount means a concentration of $10^{-9}$ $10^{-3} \mathrm{~mol} / \mathrm{L}$ [5]. However, the controlling agents of radical polymerization do not meet this criterion. For example, metal halides, which are employed in atom transfer polymerization, except the ARGET ATRP option [19], should be used in an amount an order of magnitude higher than the upper bound of the specified interval to provide the effective control of MW of the polymer. This criterion is only met by metallocenes and postmetallocenes, for example, system $\mathrm{Cp}_{2} \mathrm{ZrCl}_{2}-$ methylaluminoxane with a productivity of up to $3 \mathrm{t} \mathrm{PE/(h} \mathrm{g} \mathrm{Zr)} \mathrm{[20].}$

10. Design for biodegradation: chemical products should degrade easily upon use and should not accumulate in the environment. In this case, all efforts of researchers working in the field of polymer synthesis were and remain realizable in the reverse direction, the design of materials stable to any external stimuli. Synthetic polymers account for a small fraction of biodegradable polymers [21]. In the pre-COVID-19 era, the global polymer production was 350 million tons per year, among which biodegradable polymers make up less than one million tons [22].

11. Real-time monitoring for pollution prevention: there is need to continue development of analytical methodologies capable of real-time monitoring and control in the process of synthesis to avoid the formation of hazardous substances.

12. Accident prevention: substances used in the chemical process should be chosen so that to minimize the potential for chemical accidents (releases, explosions, fire). The quantitative measure for this principle is a parameter equal to the number of years of life lost per ton of the product. In the polymer industry, this parameter does not vary much for various processes and ranges from 0.002 to 0.005 [23].

The applicability of principles of green chemistry to polymer production was first comprehensively analyzed in 2014 by M.A. Dubé and S. Salehpour in a review paper [5]. Summing up, the authors concluded that the fulfillment of principles $2,8,9,11$, and 12 in polymer synthesis has reached considerable success; solution to problems identified in principles 1,6 , and 10 is being developed intensely; principles $3,4,5$, and 7 offer the greatest potential for the future.

At present, several reviews addressing the application of principles of green chemistry to controlled radical polymerization processes have been published. Their greater part refers to atom transfer polymerization, as the most "dirty", in terms of green chemistry, controlled polymerization technique. Noteworthy is the fact that the first review in this field was published several years earlier [24] than that mentioned above. Naturally, main attention was focused on reduction in the content of residues of catalysts, copper salts, in polymers produced by atom transfer polymerization and searching for alternative atom transfer catalysts derived from iron or nonmetallic compounds [25-30]. There are reviews covering issues of green chemistry in reversible and degenerative addition fragmentation chain transfer processes [31-33]. As a green direction in controlled radical polymerization photoinduced polymerization stands out as an approach which allows one not only to reduce energy requirements but, in some cases, to replace toxic controlling agents with nontoxic ones and to use no initiators [24, 27, 31].

As far as known, similar reviews in the field of controlled radical polymerization mediated by nitroxides as controlling agents still do not exist. Therefore, the present work should be regarded as the first attempt to analyze radical polymerization processes under reversible inhibition conditions in terms of green chemistry.

The attractiveness of nitroxide radicals for the controlled synthesis of polymers regarding the principles of green chemistry is their low toxicity. The biological 
effects of nitroxides are determined by the fact that free radicals imitate in part the activity of enzyme superoxide dismutase (SOD) [34]. This enzyme reduces the superoxide of anion radical $\left(\mathrm{OO}^{-\bullet}\right)$ which is one of the most dangerous active forms of oxygen formed in mitochondria in the process of cellular respiration. As a result, a much less strong oxidizer, hydrogen peroxide, is formed. In cells, nitroxide radicals are easily reduced to corresponding hydroxylamines under the action of superoxide, glutathione, or ascorbic acid [35-37]. Therefore, nitroxides manifest well-defined antioxidant and radioprotective properties $[38,39]$ and prevent the development of inflammation of the blood vessels of the eye [40]. The antitumor activity of nitroxide radicals is described in [41, 42].

Owing to the presence of an unpaired electron nitroxide radicals are used in medicine in MRI as contrasting agents accelerating spin relaxation and thus amplifying signal and improving resolution [43, 44].

The cytotoxicity of nitroxides manifesting on cellular cultures is registered only in millimole concentrations with five-membered cyclic nitroxide radicals being more toxic than six-membered TEMPO derivatives [45]. It is shown that when taken in millimole concentrations nitroxides possess the mutagenic behavior; however, these concentrations are almost never achieved in the study of biological effects of polymers synthesized by nitroxide-mediated polymerization [46]. The polymers obtained by this method do not exhibit noticeable cytotoxicity at concentrations on the order of $1 \mathrm{mg} / \mathrm{mL}$ [47]. Therefore, this method of controlled radical polymerization satisfies the principles of green chemistry to the highest extent.

\section{NITROXIDE-MEDIATED PHOTOPOLYMERIZATION}

Nitroxide-mediated reversible inhibition polymerization is based on the reversible capture of propagating radicals by nitroxides. One of the substantial drawbacks of this method is related to the need to maintain high temperatures [48-50]. For most widely used nitroxides, such as TEMPO (1), $N$-tert-butyl- $N$-[1-diethylphosphono(2,2-dimethylpropyl)] nitroxide (SG-1, 2), tert-butyl-1phenyl-2-methylpropyl nitroxide (TIPNO, 3), 2,2diphenyl-3-phenylimino-2,3-dihydroindol-1-yloxyl nitroxide (4), and di-tert-butyl nitroxide (5), the temperature of polymerization should be $100-130^{\circ} \mathrm{C}$. Even with more efficient agents, such as imidazoline nitroxides and SG-1, the mechanism of reversible inhibition is realized at temperatures above $70-80^{\circ} \mathrm{C}$. Therefore, the search for nitroxides "operating" at low temperatures remains an urgent problem [51-54]:

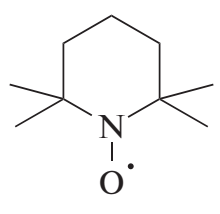

1

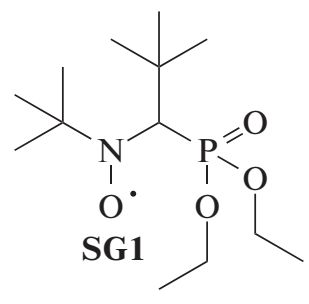

2

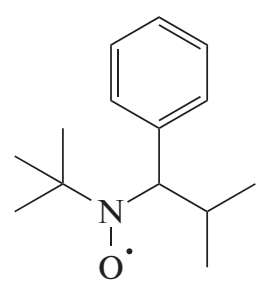

3

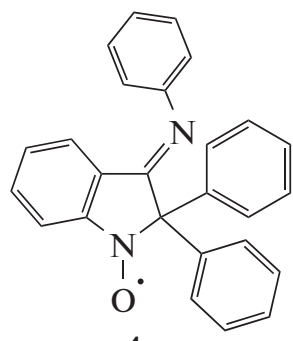

4

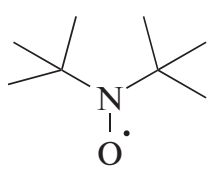

5
However, as mentioned above, reduction in the temperature of reaction is a not very effective way to implement the 6th principle of green chemistry, decrease in energy requirements, because maintaining reaction temperature is only a small part of total technological production costs. In this respect, photopolymerization is of interest not only as a method which makes it possible to decrease energy requirements but also, what is more important, as a method which may lead to an almost complete cessation of the major side reaction, the reaction of disproportionation between nitroxide and a propagating radical. The latter reaction not only yields byproducts, hydroxylamines, but also decreases the overall yield of the polymer, violates the control of MW, and widens the MWD of the product. This problem is especially pressing in the polymerization of MMA and other methacrylic monomers $[55,56]$.
The feasibility of nitroxide-mediated photopolymerization was predicted a decade before its implementation [57]. To this end, two approaches, introduction of a chromophore group into nitroxide [58] and photosensitization, were applied.

First attempts to employ photoactive alkoxyamine initiators in controlled radical polymerization failed. The authors of [58] obtained four TEMPO-based initiators: three compounds contained benzoylformyl, benzophenoneformyl, and [(xanthen-3yl)oxy]acetate groups in nitroxide, and one compound contained benzoylbenzoic group in the alkyl moiety. Unfortunately, none of them initiated the photopolymerization of styrene and only alkoxyamine carrying xanthene-substituted nitroxide initiated the polymerization of MMA via single-initiation nonliving mechanism.

Introduction of a more efficient quinoline antenna into TEMPO allowed the photopolymeriza- 
tion of styrene but upon UV irradiation of the reaction mixture for $2 \mathrm{~h}$ no more than $10 \%$ PS with $M_{\mathrm{n}}=$ $2.7 \times 10^{3}$ and $D=1.6$ was obtained [59]. As regards MW control, this nitroxide did not meet expectations in the atom transfer polymerization of MMA as well but it was efficient in the stereo control of macromolecules: in its presence the fraction of syndio triads in PMMA increased from 46 to $60 \%$ [60].
The ESR study of photodissociation of six alkoxyamine initiators $(\mathbf{6}-\mathbf{1 1})$ containing the photoactive benzophenone group in different positions with respect to the $\mathrm{N}-\mathrm{O}$ bond showed that the rate constant of photolysis is directly proportional to the intensity of light and with accuracy to the order of magnitude is proportional to the extinction coefficient of alkoxyamine [61]:<smiles>COC(=O)C(C)(C)N(OC(C)(C)C(C)=O)c1ccc(C(=O)c2ccccc2)cc1</smiles>

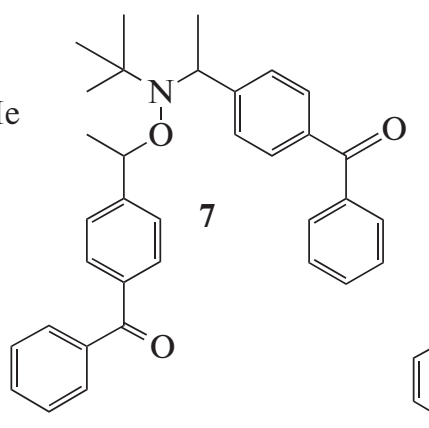<smiles>CCOC(OCC)C(C)N(OC(C)c1ccc(C(=O)c2ccccc2)cc1)C(C)(C)C</smiles><smiles>CC(ON1C(C)(C)CC(OC(=O)c2ccc(C(=O)c3ccccc3)cc2)CC1(C)C)c1ccccc1</smiles><smiles>CCOC(OCC)C(N(OC(CC(C)(C)C(=O)O)C(=O)Nc1ccc(C(=O)c2ccccc2)cc1)C(C)(C)C)C(C)(C)C</smiles>

The key factor affecting the mechanism of photolysis is the remoteness of a chromophore group from the aminoxyl function [62]. If the $\pi$ system of a chromophore is directly conjugated with the nitroxide group (compound 6), then decomposition via $\mathrm{C}-\mathrm{O}$ and $\mathrm{O}-\mathrm{N}$ bonds is feasible. For the selective cleavage of the $\mathrm{C}-\mathrm{O}$ bond the presence of a chromophore in the $\alpha$ position with respect to the nitroxide group in initiators $\mathbf{7}$ and $\mathbf{8}$ is the most favorable. Existence of the second benzophenone group in nitroxide moiety 7 has no effect on the photolysis of the initiator. As expected, the lowest photoactivity is exhibited by initiators 9-11 with the remote chromophore group.

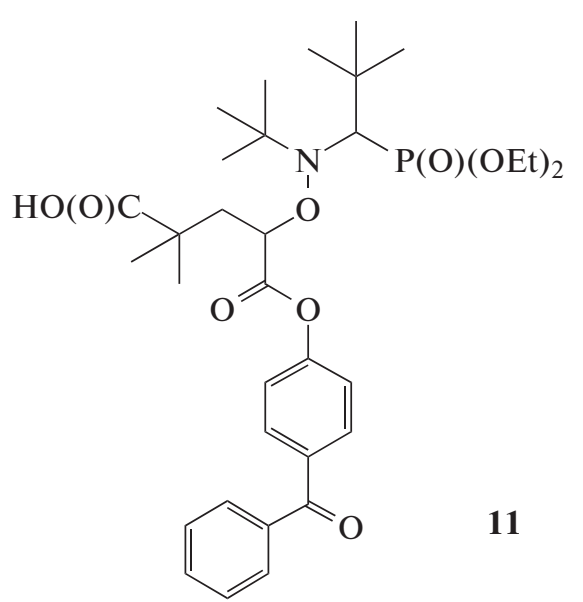

Actually, alkoxyamine 6, which undergoes photolysis to generate not only nitroxide but also alkoxide and nitrogen-centered radicals, readily initiates the photopolymerization of butyl acrylate [58, 63]. The rate of the process is higher by a factor of 4 compared with initiator 9. Conversion at room temperature attained for $8 \mathrm{~min}$ is $80 \%$. The $\mathrm{MW}$ of the polymer increases with conversion, but it is twice as high as the theoretical value and dispersion over MW grows to 4 by the end of polymerization. However, the same uncontrolled process occurs in the photopolymerization of isobornyl acrylate initiated by alkoxyamine 7 which photolizes to give rise only to nitroxides [64]. Note that the thermally initiated polymerization of 
styrene at $120^{\circ} \mathrm{C}$ mediated by alkoxyamines $\mathbf{7}$ and $\mathbf{1 1}$ proceeds in the strictly controlled mode; under the same conditions the control of molecular weight characteristics in the polymerization of isobornyl acrylate is much worse [64]. When coupled with triethylamine compound 7 it acts as a well-known redox pair benzophenone-amine initiating conventional radical polymerization [64].

As shown for the polymerization of butyl acrylate mediated by alkoxyamine 12, the higher the intensity of UV radiation $(\lambda=360 \mathrm{~nm})$, the higher the rate of photopolymerization, and the closer the values of MW to the theoretical ones; in this case, the dispersity of the product changes from 1.5 to 2.0 [63]. Styrene did not polymerize under the same conditions, while the polymerization of MMA stopped at $35 \%$ conversion when oligomers were formed. The replacement of the benzophenone antenna with naphthalene 13 or pyrene $\mathbf{1 4}$ one did not improve the control of MW. In the latter cases, visible light was used for irradiation:

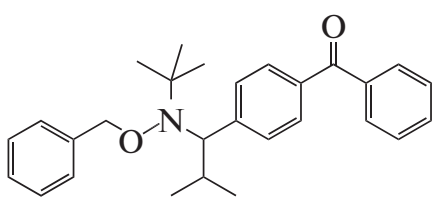

12

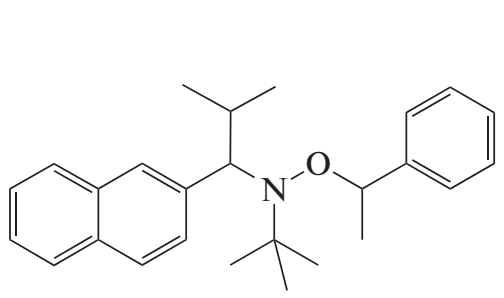

13

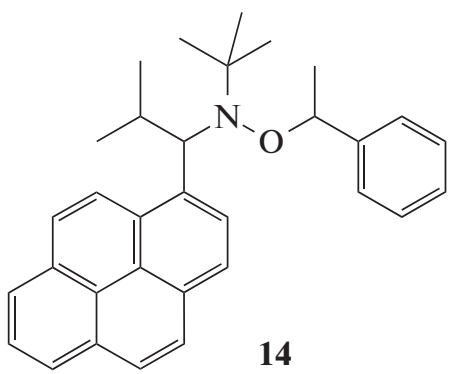

The authors of [65] studied the photopolymerization of MMA mediated by the binary system composed of both photoactive initiator and photoactive nitroxide taken in the equimolar amount: 2,2-dimethoxy-2-phenylacetophenone and 4-substituted TEMPO. The latter was used in the form of three radicals:<smiles>CC1(C)CC(ON2C(C)(C)CC(ON3C(C)(C)CC(OC(=O)c4ccc5ccccc5c4)CC3(C)C)CC2(C)C)CC(C)(C)N1[O]</smiles>

For all systems the rates of polymerization were similar. Although MW increased during the process, it was much higher than the theoretical value and dispersity changed from 1.3-1.4 at initial and medium conversions to the values above 2.0 at high conversions.

The nature of an alkyl moiety in the alkoxyamine photoinitiator exerts a considerable effect on its photolysis. In the series of compounds containing the same isoindoline nitroxide moiety with the anthraquinone antenna [66]:<smiles>[R]ON1C(C)(C)c2cc3c(cc2C1(C)C)C(=O)c1ccccc1C3=O</smiles>

where $\mathrm{R}$ is $\alpha$-methylbenzyl (15), benzyl (16), pentyl (17), $\mathrm{HOC}(=\mathrm{O})\left(\mathrm{CH}_{3}\right) \mathrm{CH}^{\bullet}(\mathbf{1 8}), \quad(\mathrm{CN})\left(\mathrm{CH}_{3}\right) \mathrm{CH}^{\bullet}$ (19), and $\operatorname{EtOC}(=\mathrm{O})\left(\mathrm{CH}_{3}\right)_{2} \mathrm{C}^{\bullet}(\mathbf{2 0})$, not all compounds can decompose under UV irradiation. Only three of them, compounds $\mathbf{1 5}, \mathbf{2 0}$, and $\mathbf{1 6}$, that is, low molecular weight models of PS and poly(ethyl methacrylate) nitroxide adducts, dissociate into radicals. The remaining, including PAN (19) and poly(methyl methacrylate) (18) models, are photostable for $8 \mathrm{~h}$. The same difference is observed for alkoxyamines based on isoindoline nitroxide with the active naphthyl antenna. The absorption band of this group is shifted to the shortwave region, that is, to the region of light quanta with a higher energy. It could be expected that styrene and alkyl methacrylates would be capable of photopolymerization mediated by photoactive derivatives of the same nitroxide while alkyl acrylates and acrylonitrile would not. In practice, neither styrene nor butyl acrylate do not polymerize under exposure to UV radiation in the presence of compound 15 and its naphthyl-substituted analog. The authors of [67] synthesized more than 30 various isoindoline alkoxyamines containing benzophenone, fluorenone, anthraquinone, naphthyl, antracenyl, and other groups and studied their photochemistry; however, the data on their use in photopolymerization, as far as we know, are limited to only several isoindoline alkoxyamines listed above. 
An ineffective attempt was made to mediate photopolymerization using photoactive macronitroxides which were obtained via polymerization in situ from nitrones with benzophenone (21), naphthalene (22 and 23), and pyrene antennas (24) $[63,66]$ :<smiles>CC(C)(C)[N+](=O)/C=C/c1ccc(C(=O)c2ccccc2)cc1</smiles>

21<smiles>CC(C)(C)N([O-])C=Cc1ccc2ccccc2c1</smiles>

22<smiles>CC(C)(C)[N+]([O-])=Cc1cccc2ccccc12</smiles>

23<smiles>CC(C)(C)[N+]([O-])=Cc1ccc2ccc3cccc4ccc1c2c34</smiles>

24
PS macroinitiators synthesized by thermal polymerization initiated by systems AIBN-21 at $125^{\circ} \mathrm{C}$ and AIBN-22 and AIBN-23 at $60^{\circ} \mathrm{C}$ which contained a photoactive group within chain acted as single photoinitiators of butyl acrylate polymerization yielding the ABA-type block copolymer:<smiles>CC(C)(C)CC(ON(C(C)(C)C)C(C)(Cc1ccc2ccccc2c1)C(C)(C)C(C)(C)C)c1ccccc1CC(C)(C)C#N</smiles>

The products contained a large amount of unreacted PS. The mechanism of single photoinitiation was also operative in the polymerization of butyl acrylate mediated by PS with a benzophenone photoactive group within chain which was synthesized by the click reaction rather than the polymerization technique. Polystyrene synthesized using system AIBN-24 almost did not initiate photopolymerization. Note that the enumer- ated PS samples behave likewise in the initiation of thermal polymerization of butyl acrylate at $120^{\circ} \mathrm{C}$.

The reason behind violation of the controlled mechanism of photopolymerization may be the degradation of acyclic nitroxides under UV irradiation. For example, the irradiation of di-tert-butyl nitroxide leads to generation of a nonradical adduct [68]:

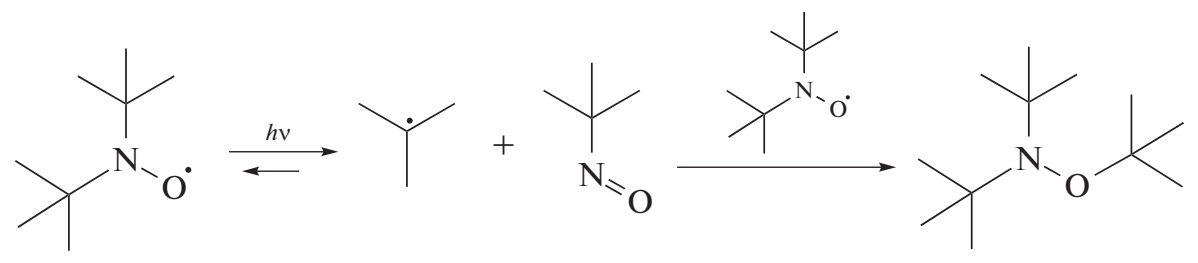

In contrast, cyclic nitroxides (TEMPO, proxyl, isoindoline) are much more stable, since nitrone resulting from their degradation easily captures nearby C-centered radical which shifts the equilibrium of dissociation to the left $[69,70]$ :<smiles></smiles> 
A long UV irradiation of TEMPO and its derivatives does not induce their photolysis but leads to the formation of hydroxylamine via the splitting of proton from the surrounding medium by nitroxide [71].

The authors believe that the main reason behind a poor control of nitroxide-mediated photopolymerization is a low rate of reinitiation [66]. It is not impossible that nitroxide loaded with a photo antenna possesses a low inhibitory activity.

In view of the foregoing, the results of Chinese scientists seem amazing [72]. They managed to implement the emulsion photopolymerization of MMA using common nitroxide, 4-hydroxy-TEMPO, and photoinitiator Irgacure-184 at room temperature. Even though neither nitroxide nor polymer contained chromophore groups, the authors observed a linear growth of $M_{\mathrm{n}}$ of the polymer with conversion and $D=$ 1.27-1.36. Unfortunately, the mechanism of photoinitiation was not discussed in [72].

The second direction, photopolymerization carried out using photosensitizers, was studied in most detail by E. Yoshida [73] for the polymerization of MMA performed using an azo initiator, 4-methoxyTEMPO, and a number of cationic photoinitiators. Bis(alkylphenyl)iodonium hexafluorophosphate (alkyl $=\mathrm{C}_{10}-\mathrm{C}_{14}$ ) used a photoinitiator was added in an amount comparable with that of nitroxide. Initially it was assumed that these compounds function like photoacid generators in cationic polymerization [74], but later a typical free-radical photosensitizing mechanism was unveiled [75]. Upon the introduction of diaryliodonium salt the rate of polymerization and the MW of the polymer increased but MWD became much broader $(\theta \sim 3.2)$. The sensitizer himself did not enter the composition of a macromolecule: according to ${ }^{1} \mathrm{H}$ NMR spectroscopy, the polymer contained an azo initiator moiety and nitroxide at chain ends. In this case, the kinetics of the process was of the first order with respect to the monomer concentration and the $M_{\mathrm{n}}$ of the polymer linearly increased with conversion.

The nature of an azo initiator insignificantly influenced the yield and molecular weight characteristics of PMMA; they were determined only by the initiatorto-nitroxide molar ratio [76]. At their equivalent ratio polymerization occurred quantitatively for $3 \mathrm{~h}$ and afforded a polymer with $M=(30-40) \times 10^{3}$ and $D>3$. At the twofold excess of methoxy-TEMPO the yield and MW decreased by 2 to 3 times and dispersity became as low as 1.5-1.7.

The authors advanced the cation radical mechanism for polymerization photoreinitiation which included equilibrium between the polymer-nitroxide adduct, MMA propagating radical, and 4-methoxyTEMPO cation:

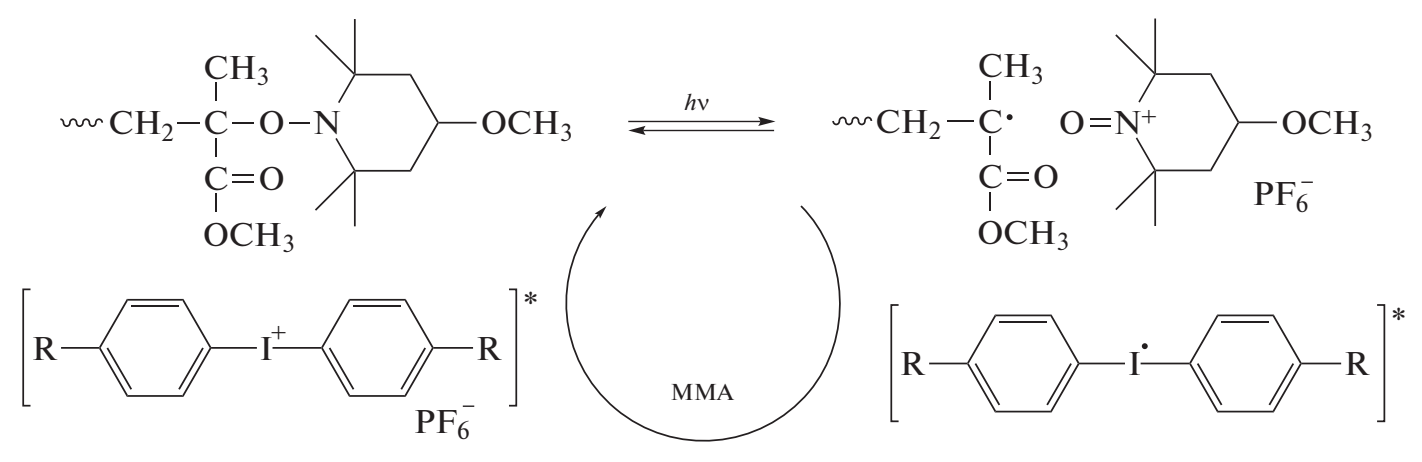

This mechanism is evidenced by the fact that upon the addition of triphenylamine, a compound decomposing the cationic form of nitroxide, in the system, photopolymerization becomes uncontrollable [75].

A similar behavior is exhibited by other cationic photoinitiators, various salts of triarylsulfonium and

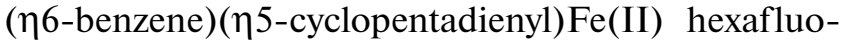
rophosphate [77, 78]. The living mechanism of MMA photopolymerization was also observed when 4-methoxy-TEMPO was replaced with macronitroxide 4-(poly-THF)-TEMPO [79].

It is reported that these systems can be used to perform the photopolymerization of MMA in acetonitrile [77] and the dispersion polymerization of MMA in the medium methanol-water [80]. However, in both cases, the living mechanism of polymerization is violated.

The photopolymerization of glycidyl methacrylate carried out using (4-tert-butylphenyl)diphenylsulfonium triflate coupled with nitroxide proceeds in a similar manner. During the reaction the cleavage of only double bonds $\mathrm{C}=\mathrm{C}$ of the monomer rather than of the epoxy cycle is observed. This confirms the radical mechanism of photopolymerization [81].

Interestingly, when under the same conditions the binary system azo initiator-4-methoxy-TEMPO was replaced with the alkoxyamine initiator 1-(cyano-1methylethoxy)-4-methoxy-2,2,6,6-tetramethylpiperidine, the adduct of an AIBN moiety with the same nitroxide, the control over the MW of the polymer 
worsened considerably and MWD became broader [82]. In this case, the mechanism of polymerization photoinitiation changed dramatically: the iodonium salt itself became an initiator, as evidenced by the presence of end phenyl groups in PMMA. The author proposed the following mechanism of photoinitiation [73]:

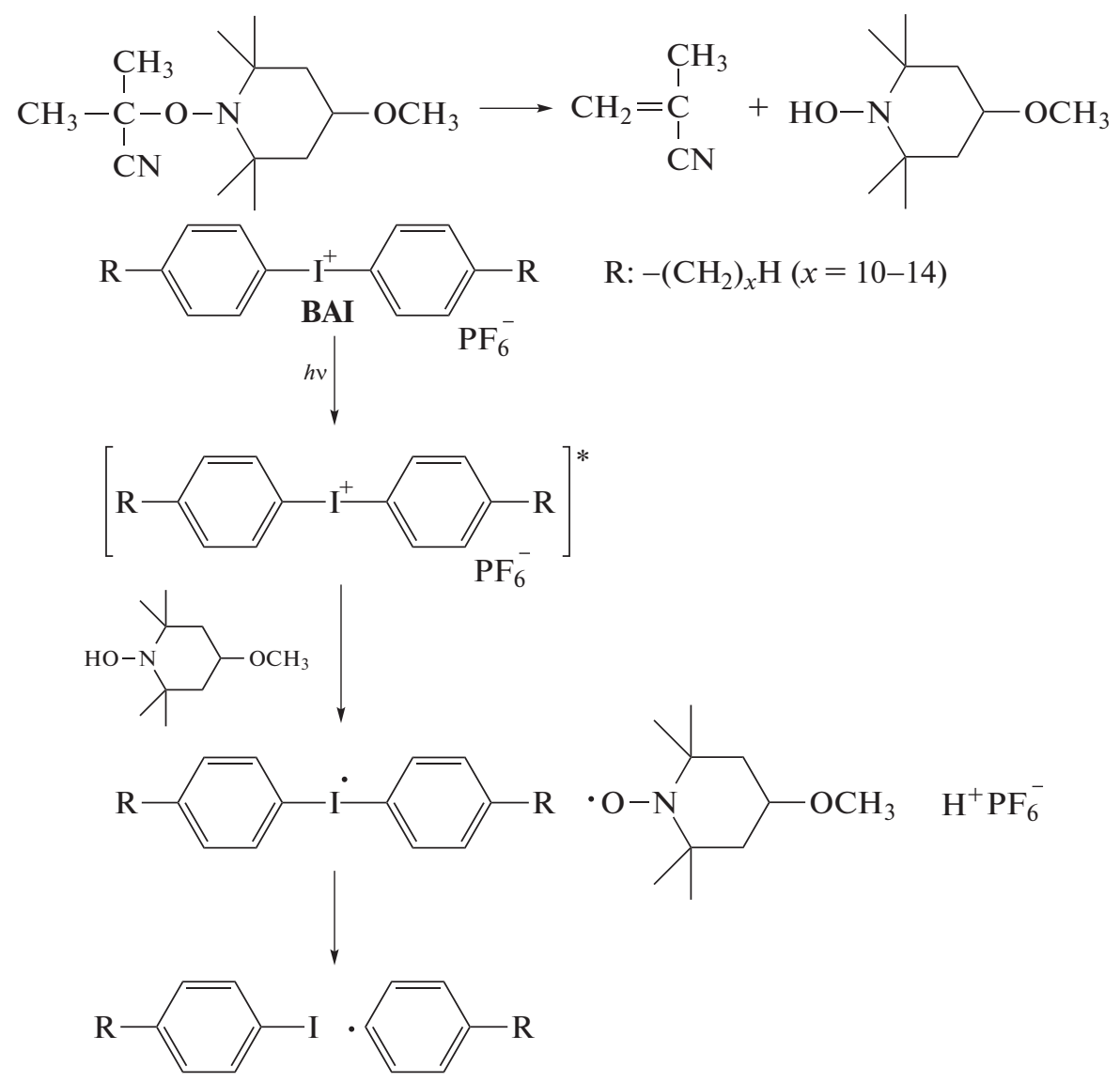

Thus, even though photopolymerization makes it possible to realize nitroxide-mediated polymerization under milder conditions, in terms of control of molecular weight characteristics, it markedly ranks below conventional high-temperature polymerization. Nevertheless, just this process has already been actively used for manufacturing luminescent coatings, laser photoprinting, and synthesis of functional polymer multilayers on the surface of silicon plates [83-86]. Theoretical work also continues in this field [87].

\section{DISPERSION POLYMERIZATION IN SUPERCRITICAL CARBON DIOXIDE}

Radical polymerization in various aqueous dispersion media (emulsion, microemulsion, miniemulsion, suspension, precipitation) is treated in green chemistry as an eco-friendly alternative to technological processes in bulk or organic solvents [24, 33, 88]. Reversible-deactivation controlled radical polymerization (atom transfer and nitroxide-mediated) performed under heterogeneous conditions is distinguished by special kinetic effects that influence the molecular weight characteristics of the products $[89,90]$.
Various techniques of nitroxide-mediated dispersion polymerization were developed intensely almost immediately after the advent of this process. At present, a huge amount of information in the field has been accumulated and summarized in several reviews [91-96]. Within the framework of this review we will limit ourselves to a relatively new direction rapidly developing during the past decade and a half, nitroxide-mediated precipitation and dispersion polymerizations in supercritical carbon dioxide $\left(\mathrm{scCO}_{2}\right)$. Just polymerization mediated by nitroxides made a much greater progress in this field compared with other controlled radical polymerization techniques [92].

For carbon dioxide the supercritical state is realized under relatively mild conditions: $T_{\mathrm{sc}}=31^{\circ} \mathrm{C}$ and $P_{\mathrm{sc}}=$ 7.4 MPa [97]. This nontoxic, inexpensive, nonflammable, and easily removable solvent meets principles of green chemistry. It is characterized by an order of magnitude lower viscosity and one to two orders of magnitude higher diffusion of reagents compared with common organic media. Almost all polymers (except fluorinated and silicon polymers) are insoluble in 
Table 1. Conditions of styrene polymerization in $\mathrm{scCO}_{2}$ and characteristics of the product

\begin{tabular}{l|c|c|c|c|c|c|c|c}
\hline \multicolumn{1}{c|}{ System } & $w^{*}, \%$ & $T,{ }^{\circ} \mathrm{C}$ & $P, \mathrm{MPa}$ & Time, $\mathrm{h}$ & Yield, $\%$ & $M_{\mathrm{n}} \times 10^{-3}$ & $D$ & References \\
\hline AIBN-TEMPO-SO $\mathrm{SO}_{2}$ & - & 125 & 26.8 & 18 & - & 29.9 & 1.6 & {$[98]$} \\
$\mathrm{Bz}_{2} \mathrm{O}_{2}-\mathrm{TEMPO}-\mathrm{CF}_{3}\left(\mathrm{CF}_{2}\right)_{7} \mathrm{SO}_{3} \mathrm{H}$ & - & 125 & 26.7 & 24 & 86 & 1.67 & 1.6 & {$[99]$} \\
$\mathrm{AIBN}-\mathrm{SG}-1$ & 60 & 110 & 42 & 48 & 95 & 19.1 & 1.45 & {$[100]$} \\
$\mathrm{AIBN}-\mathrm{SG}-1$ & 70 & 110 & $30 \pm 5$ & - & 82 & 23.8 & 1.36 & {$[101,102]$} \\
$\mathrm{AIBN}-\mathrm{TIPNO}$ & 70 & 110 & $30 \pm 5$ & - & 29 & 16.0 & 1.26 & {$[101,102]$} \\
Compound 25 & 40 & 110 & 30 & 61 & 39 & 20.0 & 1.29 & {$[103]$} \\
Compound 26 & - & - & - & 69 & 38 & 19.5 & 1.32 & - \\
\hline
\end{tabular}

*Weight fraction of the monomer.

$\mathrm{scCO}_{2}$ [92]. Therefore, polymerization in $\mathrm{scCO}_{2}$ proceeds in the precipitation mode.

The polymerization of styrene mediated by nitroxides of various nature in $\mathrm{scCO}_{2}$ was studied in most length. The first two patents on the manufacture of PS with the participation of TEMPO in $\mathrm{scCO}_{2}$ were got by Xerox already in 1996 [98, 99]. Further studies were carried out under similar conditions (Table 1). The polymerization of styrene carried out at $110^{\circ} \mathrm{C}$ using the system AIBN-SG-1 proceeds to ultimate conversions; $M_{\mathrm{n}}$ nonlinearly grows with conversion but $D$ changes from 1.12 to 1.35 [100]. As regards molecular weight characteristics, PS synthesized by precipitation polymerization in $\mathrm{scCO}_{2}$ is almost the same as the polymer synthesized under the same conditions in bulk or toluene solution at atmospheric pressure. Moreover, at a high content of the monomer (70 wt \%) its dispersity is even lower compared with the polymer prepared under homogeneous conditions. However, the rate of the precipitation process is 1.6 times lower than that in bulk.
Upon replacement of nitroxide SG-1 with TIPNO the rate of polymerization in $\mathrm{scCO}_{2}$ decreased by almost half, the MW of the polymer increased, and MWD broadened [101]. To achieve a good control over MW in $\mathrm{scCO}_{2}$ no less than a 2-fold excess of SG-1 and a 3.3-fold excess of TPIN with respect to AIBN were required. The MWD of polystyrene synthesized with SG-1 as a mediator was independent of monomer concentration, while for the polymer synthesized using TPIN in $40 \%$ solution of the monomer MWD was even narrower than that in $70 \%$ solution. According to the authors, these differences can be explained by the different solubility of polar SG-1 and nonpolar TIPNO in $\mathrm{scCO}_{2}$ and styrene [102].

To improve the solubility of nitroxide in $\mathrm{scCO}_{2}$ (and, accordingly, to improve the control of MW), for the precipitation polymerization of styrene, the authors of [103] recently synthesized new alkoxyamine initiators containing perfluoroalkyl groups:

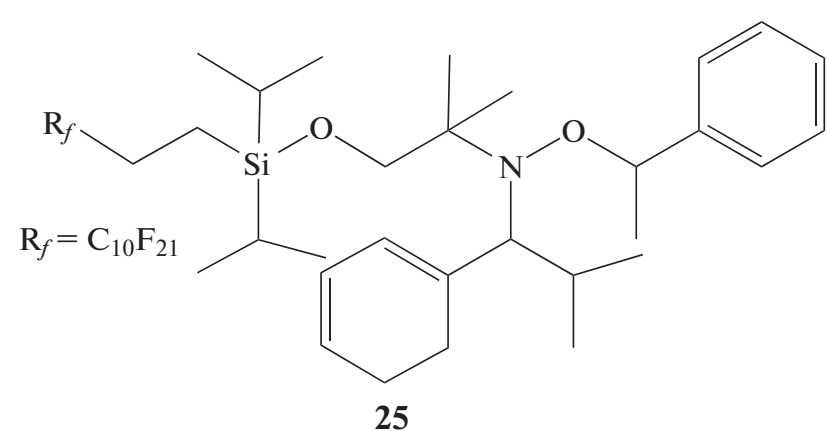

However, the rate of polymerization was lower than the rate of polymerization mediated by SG-1 or TIPNO. The molecular weight characteristics of PS were unaffected by the position of the fluorinated group: in the alkyl moiety of the initiator or nitroxide (Table 1) [104].

It is interesting that when polymeric alkoxyamines containing analogous perfluoroalkyl acrylate substituents were used as initiators styrene did not polymerize.

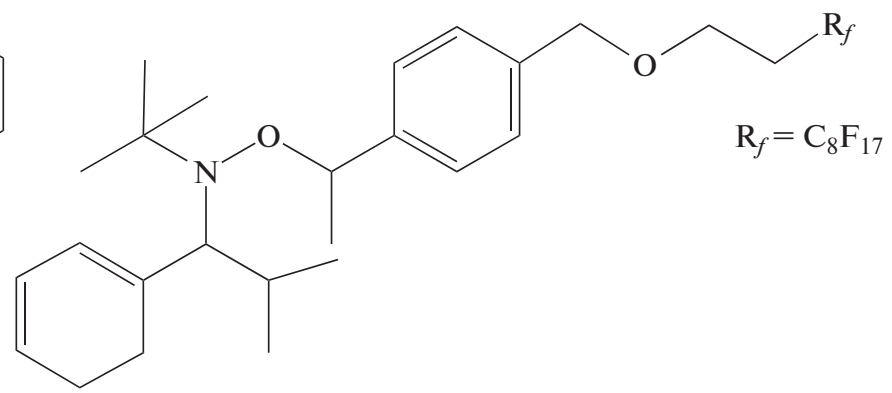

26

The nitroxide-mediated precipitation polymerization of tert-butyl acrylate and dimethylacrylamide in $\mathrm{scCO}_{2}$ is described in [105]. The polymerization of the first monomer performed using the system AIBNSG-1 (50 wt $\left.\%, 118^{\circ} \mathrm{C}, 30 \mathrm{MPa}\right)$ proceeds by the reversible inhibition mechanism: $M_{\mathrm{n}}$ linearly increases with conversion, and $D$ amounts to $1.3-1.7$. The living mechanism was also observed for polymerization of 
the second monomer $\left(20\right.$ wt $\left.\%, 120^{\circ} \mathrm{C}, 30 \mathrm{MPa}\right)$. In both cases, a 3-fold excess of nitroxide with respect to the initiator was required; the fraction of living chains by the end of the process was $82 \%$. Both polymers can reinitiate the polymerization of styrene accompanied by the formation of block copolymers [106].

Dispersion polymerization in $\mathrm{scCO}_{2}$ is usually carried out in the presence of an amphiphilic block copo- lymer; polydimethylsiloxane more often serves as a $\mathrm{CO}_{2}$ philic block. The SG-1-mediated dispersion polymerization of styrene was studied in length in [107-109].

In the first run on the nitroxide-mediated dispersion polymerization of styrene, PDMS VPS-0501 containing 6-10 azo groups in a chain was used as an initiator and stabilizer [107]

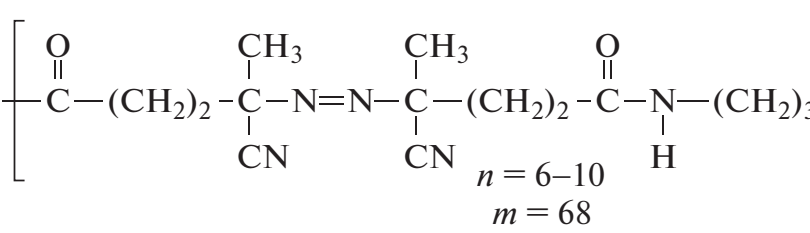

$m=68$

During the decomposition of azo groups PDMS initiated polymerization and transformed into a block copolymer stabilizing dispersion. Styrene was polymerized out using the system VPS-0501/SG-1 (or TEMPO) at $100^{\circ} \mathrm{C}$ and a pressure of $42 \mathrm{MPa}$. In both systems, conversion was below $20 \%$ and MWD was bimodal. The latter fact was attributed to the formation of two types of block copolymers, PS-blockPDMS and PS-block-PDMS-block-PS.

Controlled dispersion polymerization was accomplished according to several approaches: (i) decrease in the concentration of PDMS from 20 to $1.5 \%$ and the use of AIBN as the main initiator, (ii) an increase in the ratio of SG-1 : AIBN to 3.5, and (iii) partial decomposition of PDMS and thus a reduction in the number of azo groups in a chain to two. As a result, the block copolymer with a yield of $90 \%, M_{\mathrm{n}}=5 \times 10^{4}$, and $D=1.6$ was obtained. Under all conditions irregular particles with a wide size distribution were formed.

For the polymer with the monomodal MWD the stabilizer was a polymer synthesized by dispersion polymerization mediated by nitroxides. For example, triblock copolymer SG-1-PS-block-PDMSblock-PS-SG-1 synthesized according to the above technique was used as an initiator and stabilizer in the polymerization of styrene in $\mathrm{scCO}_{2}$ [107]. However, in this case, MWD was also bimodal which was explained by impurity of the monofunctional initiator in the block copolymer.

Polystyrene with the monomodal MWD and $D \sim$ 1.3 was synthesized using diblock copolymer PDMSPS-SG-1 which was prepared via atom-transfer polymerization followed by radical replacement of the end group Br with SG-1 [109]. Spherical particles with an average diameter of $132 \mathrm{~nm}$ were produced. Similar data were obtained for the commercially available stabilizer PDMS-block-PMMA (42 MPa, $110^{\circ} \mathrm{C}, 40 \%$ ) [108].

The "initiator-stabilizer" approach was effective in the dispersion copolymerization of MMA with $9 \%$ styrene in $\mathrm{scCO}_{2}\left(30 \mathrm{MPa}, 70^{\circ} \mathrm{C}\right)$ [110]. Macroinitiator SG-1-terminated poly(heptadecafluorodecyl acrylate) was used as a stabilizer. The yield of the copolymer was about $90 \%, M_{\mathrm{n}}$ was close to theoretical, and $D=1.26-1.31$. Spherical particles with the narrow distribution over size $16 \pm 2 \mu \mathrm{m}$ were obtained.

Using TEMPO-mediated dispersion polymerization the block copolymer PS-block-poly(butyl acrylate) was synthesized [111]. Various block copolymers PDMS-block-PS and poly $(3,3,4,4,5,5,6,6,7,8,8,8$ dodecafluoro-7-(trifluoromethyl)octyl methacrylate)-block-PS were used as stabilizers. The best control over MW was achieved in the case of the fluorinated copolymer.

Monomers poorly soluble in $\mathrm{scCO}_{2}$ were involved in inverse suspension polymerization [106, 112, 113]. For example, the polymerization of $N$-isopropylacrylamide (NIPAM) was carried out at a pressure of 27$30 \mathrm{MPa}$, a temperature of $120^{\circ} \mathrm{C}$, and a monomer concentration of $10 \mathrm{wt} \%$ using AIBN and SG-1. Under these conditions NIPAM melted and formed droplets of suspension in $\mathrm{scCO}_{2}$. In this case, an almost complete conversion of the monomer was attained, the $M_{\mathrm{n}}$ of the polymer linearly increased with conversion, and $Ð$ changed from 1.3-1.4 at the onset of the process to 2.0 at high conversions. Block copolymers polydimethylacrylamide (PDMA)-block-PNIPAM, poly(tert-butyl methacrylate) (PTBA)-block-PNIPAM, poly(acrylic acid)-block-PNIPAM, and PSPNIPAM were synthesized by the sequential polymerization of monomers (Table 2).

In concluding this section, let us mention the practical application of this method for the synthesis of graft copolymers for medical applications [114]. With this aim in view, the copolymer styrene-maleic anhydride was grafted onto high molecular weight chitosan in $\mathrm{scCO}_{2}$. Initially $19 \% \mathrm{OH}$ groups in chitosan were replaced with 4-hydroxy-TEMPO via chemical modification. The as-modified chitosan initiated the grafting dispersion copolymerization of styrene and maleic anhydride. 
Table 2. Molecular weight characteristics of block copolymers synthesized in $\mathrm{scCO}_{2}$ in the presence of nitroxide SG-1 [113]

\begin{tabular}{l|c|c}
\hline \multicolumn{1}{c|}{ Block copolymer* } & $M_{\mathrm{n}}, 10^{3}$ & $\emptyset$ \\
\hline PDMA $_{58}-$ PNIPAM $_{82}$ & 13.4 & 1.5 \\
PDMA $_{58}-$ PNIPAM $_{117}$ & 21.4 & 1.6 \\
PDMA $_{58}-$ PNIPAM $_{217}$ & 29.2 & 2.1 \\
PTBA $_{62}-$ PNIPAM $_{81}$ & 20.6 & 1.4 \\
PTBA $_{62}-$ PNIPAM $_{192}$ & 30.7 & 1.3 \\
PTBA $_{62}-$ PNIPAM $_{254}$ & 34.6 & 1.3 \\
PS $_{62}-$ PNIPAM $_{266}$ & 34.2 & 1.5 \\
\hline
\end{tabular}

*Index implies the degree of polymerization of the block.

\section{POLYMERIZATION OF MONOMERS OF BIOLOGICAL ORIGIN}

As noted above, the polymerization of monomers derived from renewable natural resources (usually of plant origin) is considered one of the promising directions in green chemistry. These are basically mono-

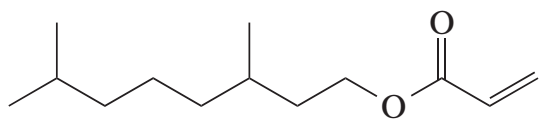

in toluene and miniemulsion mediated by alkoxy-

amine Dispolreg 007

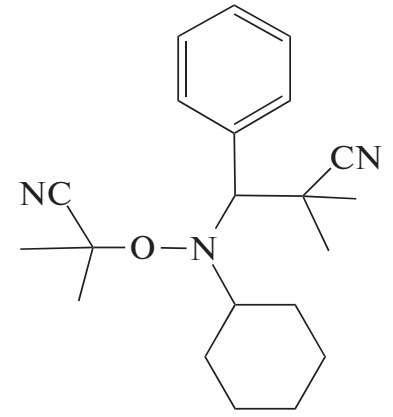

described in [122]. Polymerization proceeds to high conversions at $97^{\circ} \mathrm{C}$. The controlled mode is realized up to a degree of polymerization of $P_{\mathrm{n}}=200$ during synthesis in solution and $P_{\mathrm{n}}=500$ with dispersity $D=$ 1.2-1.4 during synthesis in miniemulsion.

The sequential polymerization of the given methacrylates yielded soft/hard block copolymers with $M_{\mathrm{n}}=(7-12) \times 10^{4}$, in which the elastic block was the polytetrahydrogeraniol derivative and the glassy block was the polycyclademol derivative [122].

Another example of monomers synthesized by the chemical modification of natural raw materials is iso- mers for polycondensation or ionic ring-opening polymerization [115]; less often, for cationic and controlled radical polymerizations [116, 117].

Vinyl compounds of bio origin are extremely rarely used directly in controlled radical polymerization. More often scientists find a compromise solution in the form of monomers produced by the chemical modification of biological raw materials, for example, derivatives of itaconic acid and (meth)acrylic esters of terpenes, which were tested in atom transfer polymerization and reversible addition fragmentation chain transfer processes [115, 118-121].

The controlled synthesis of polymers from terpene derivatives, cyclademol acrylate and cyclademol methacrylate<smiles>C=CC(=O)OC(C)C1CCCC(C)(C)C1</smiles><smiles>C=C(C)C(=O)OC(C)C1CCCC(C)(C)C1</smiles>

and tetrahydrogeraniol acrylate and tetrahydrogeraniol methacrylate
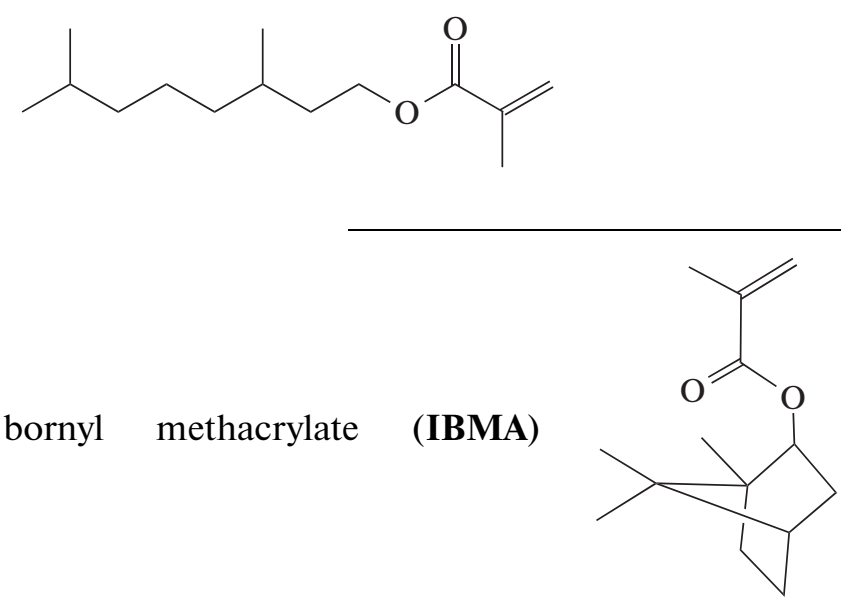

obtained from camphene and methacrylic acid as well as C-13-MA, a mixture of alkyl methacrylates with an average carbon number in the alkyl group of 13. Their polymerization and copolymerization in toluene solution at $90-110^{\circ} \mathrm{C}$ mediated by alkoxyamine Dispolreg 007 occurred with an incomplete conversion $(<80 \%)$ [123]. According to the authors, this is associated with a high viscosity of the polymerization product [123]. Under the same conditions miniemulsion polymerization proceeded almost quantitatively. However, in both cases, MW was several times higher than the theoretical value and $D$ was $1.39-1.66$ for polymerization in solution and 1.50-1.73 for polymerization in miniemulsion. The ternary copolymerization of the said monomers with methacryloyl silsesquioxane proceeded in a similar manner [124]. The sequential 
polymerization of monomers makes it possible to synthesize their block and gradient copolymers.

The miniemulsion block copolymerization of IBMA and C-13-MA initiated by a macroinitiator, SG-1-terminated copolymer of oligo(ethylene glycol methacrylate) with acrylonitrile, also occurs by the reversible inhibition mechanism and is accompanied by a linear growth of $M_{\mathrm{n}}$ of the product with conversion but $D$ is close to two [125].

A comparative study of the copolymerization of methyl cinnamate (methyl ester of cinnamic acid) mediated by various types of radical polymerization controlling agents, namely, $\mathrm{RuCpCl}\left(\mathrm{PPh}_{3}\right)_{2}$ (atom transfer polymerization), 2-cyano-2-propyl ethyl trithiocarbonate (reversible addition fragmentation chain transfer polymerization), and nitroxide TIPNO, demonstrated that control is feasible in all systems. The derivative itself as a 1,2-disubstituted vinyl compound is uninvolved in homopolymerization but easily copolymerizes with both styrene and methyl acrylate. In all cases, chain growth occurs regioselectively via the attack of styrene or acrylate radical at the carbon atom nearest to the ester carbon of methyl cinnamate to generate the propagating radical of styrene. In these systems, $M_{\mathrm{n}}$ linearly increases with conversion and $D=1.05-1.20$ for copolymerization with styrene and $D=1.2-1.4$ for copolymerization with methyl acrylate.

Nonmodified terpenes, highly active dienes, such as $\beta$-myrcene (7-methyl-3-methylene-1,6-octadiene) [126-128], a component of essential oils of laurel, ylang-ylang, wild thyme, lemongrass, and juniper, can also be polymerized by the nitroxide-mediated reversible inhibition mechanism. Its polymerization product is a valuable low-temperature elastomer with a glass transition temperature of $-75^{\circ} \mathrm{C}$ [129]:

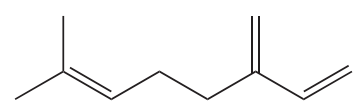

The polymerization of $\beta$-myrcene mediated by the SG-1-based alkoxyamine (BlocBuilder) occurs up to $70 \%$ conversion for $200-400 \mathrm{~min}$ [126]. The rate of reaction is of the first order with respect to the monomer, the $M_{\mathrm{n}}$ of the product linearly increases with conversion, and $D$ is close to 1.2. The product of propagation rate constant $k_{\mathrm{p}}$ by the constant of equilibrium $K$ between dormant and growing chains characterizes the livingness of the process and in the order of magnitude of $k_{\mathrm{p}} K=4.3 \times 10^{-5} \mathrm{~s}^{-1}$ corresponds to the value observed in the controlled polymerization of styrene. Under the same conditions $\beta$-myrcene is easily involved in controlled copolymerization with styrene to afford block and random copolymers. In the latter case, its activity is almost an order of magnitude higher compared with styrene $\left(r_{1}=1.88 \pm 0.12, r_{2}=0.25 \pm 0.04\right)$.

The copolymerization of $\beta$-myrcene with IBMA mediated by the SG-1-based macroinitiator Bloc-
Builder at $100^{\circ} \mathrm{C}$ yields gradient copolymers [127]. The activity of $\beta$-myrcene is higher than that of IBMA by two orders of magnitude $\left(r_{1}=1.90-2.16, r_{2}=0.02-\right.$ $0.07)$; therefore, polymerization affords macromolecules the head of which is enriched in terpene and the tail is enriched in methacrylate. IBMA does not polymerize under the same conditions via the reversible inhibition mechanism; therefore, its copolymerization with myrcene proceeds in the decaying mode. The controlled synthesis of $\beta$-myrcene random copolymers mediated by a given macroinitiator was investigated in detail in the PhD thesis [128]. It is interesting that all the synthesized copolymers have a narrow MWD and their MW is much lower than the theoretical value (Table 3 ).

A similar behavior is exhibited by another terpene 1,3-diene with a close structure, farnesene [130]:

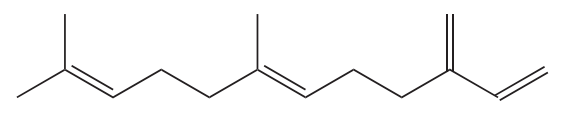

Its copolymerization with glycidyl methacrylate mediated by the BlocBuilder alkoxyamine proceeds like the copolymerization of $\beta$-myrcene with IBMA. However, when the initiator was replaced with Dispolreg 007 the control of the process was lost and the copolymer with the bimodal MWD was formed.

\section{SYNTHESIS OF EASILY DEGRADABLE POLYMERS}

Synthetic biodegradable or easily hydrolyzable polymers are produced by either polycondensation or ionic polymerization of heterocycles [131-133]. Nevertheless, several strategies, which allow the controlled synthesis of these polymers by controlled radical polymerization techniques, were detailed in recent reviews [134, 135]. They can be reduced to three options: insertion of easily degradable units into a polymer chain, block or grafting copolymerization accompanied by the formation of degradable blocks, and crosslinking of polymers by easily degradable crosslinks.

The first idea, which was advanced for the synthesis of easily degradable polymers via nitroxide-mediated controlled polymerization, consisted in the involvement of cyclic oxygen-containing vinyl monomers, ketene acetals, in this process. It should be mentioned that similar syntheses had already been known. For example, the controlled ring-opening polymerization of 2-methylene-1,3-dioxepane carried out using system di-tert-butyl peroxide-TEMPO at $125^{\circ} \mathrm{C}$ was described already in 1996 [136, 137]. The authors proposed the following mechanism of polymerization: 


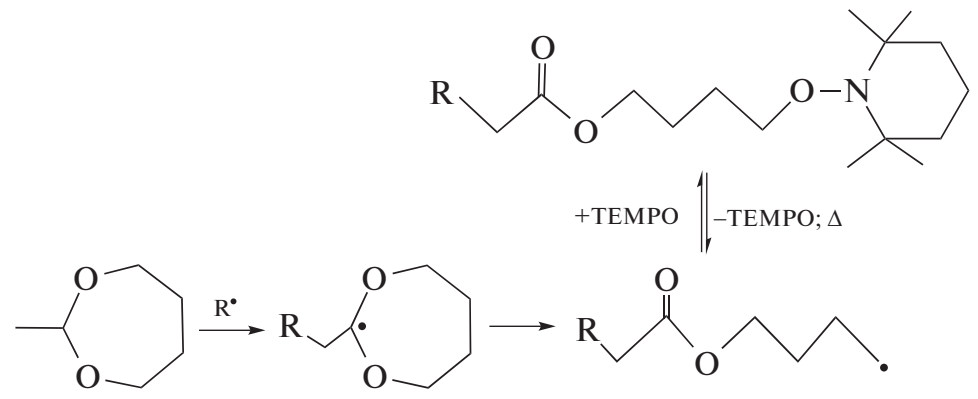

The ring-opening polymerization of two cycles, 2-methylene-1,4,6-trioxaspiro[4,4]nonane and 8,9-benzo-2-methylene-1,4,6-trioxaspiro[4,4]nonane, mediated by TEMPO which occurs by the reversible inhibition mechanism was described almost simultaneously [138, 139]:<smiles>C=C1COC2(CCCO2)O1</smiles>

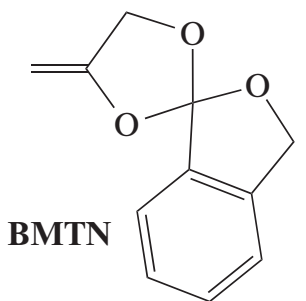

However, no data on degradation of the resulting polymers was available at that time.

The targeted synthesis of degradable polymers in the presence of ketene acetals was reported in a series of papers by French researchers [47, 140-143]. With this aim in view they synthesized 5,6-benzo-2-methyl-

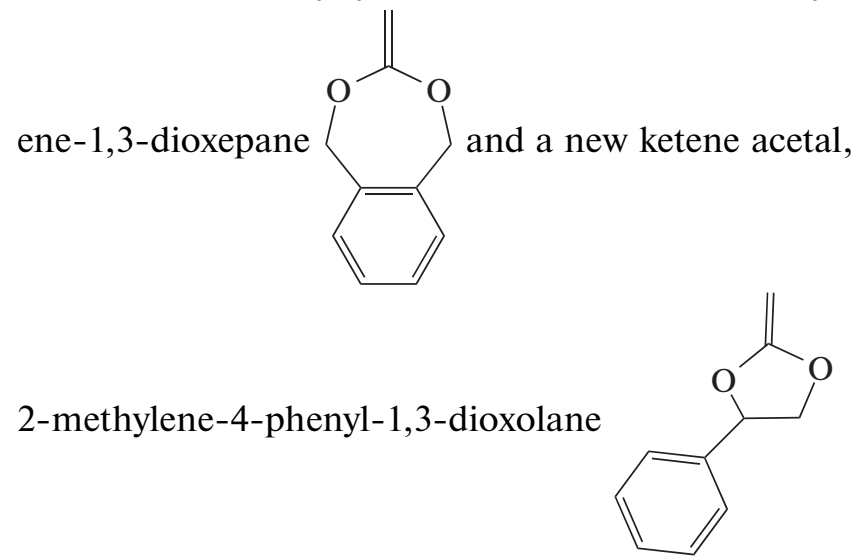

It was shown that the homopolymerization of these monomers initiated by the BlocBuilder macroinitiator at $110-130^{\circ} \mathrm{C}$ provides a poor control of MW [140]. In contrast, in the radical copolymerization of

Table 3. Molecular weight characteristics of $\beta$-myrcene random copolymers [113]

\begin{tabular}{l|c|c|c|c|c}
\hline \multicolumn{1}{c|}{ Comonomer $\left(\mathrm{M}_{2}\right)$} & Myrcene $: \mathrm{M}_{2}$ & Conversion, $\%$ & $M_{\mathrm{n}} \times 10^{-3}$ & $M_{\mathrm{n} \text { (theor) }} \times 10^{-3}$ & $D$ \\
\hline Methyl acrylate & $1: 9$ & 46 & 5.5 & 29 & 1.23 \\
tert-Butyl acrylate & $1: 9$ & 65 & 16.7 & 40 & 1.31 \\
tert-Butyl acrylate & $3: 7$ & 66 & 10.4 & 43 & 1.19 \\
Methyl methacrylate & $1: 1$ & 85 & 6.4 & 39 & 1.25 \\
Methyl methacrylate & $1: 1$ & 59 & 8.4 & 30 & 1.24 \\
Styrene & $9: 1$ & $47 / 39^{*}$ & 12.6 & - & 1.25 \\
Styrene & $7: 3$ & $41 / 37^{*}$ & 8.4 & - & 1.24 \\
Styrene & $1: 1$ & $50 / 45^{*}$ & 11.7 & - & 1.19 \\
Styrene & $3: 7$ & $54 / 45^{*}$ & 13.9 & - & 1.24 \\
Styrene & $1: 9$ & $84 / 78^{*}$ & 19.8 & - & 1.31 \\
Isobornyl methacrylate & $9: 1$ & $86 / 36^{*}$ & 18.3 & - & 1.57 \\
Isobornyl methacrylate & $7: 3$ & $84 / 32^{*}$ & 10.9 & - & 1.35 \\
Isobornyl methacrylate & $1: 1$ & $75 / 30^{*}$ & 9.4 & - & 1.28 \\
Isobornyl methacrylate & $3: 7$ & $78 / 35^{*}$ & 7.5 & - & 1.29 \\
Isobornyl methacrylate & $1: 9$ & $30 / 67^{*}$ & 5.9 & - & 1.34 \\
\hline
\end{tabular}

*Conversion of myrcene/comonomer. 
2-methylene-4-phenyl-1,3-dioxolane with MMA under the same conditions at a molar fraction of acetal $\geq 20 \%$ the $M_{\mathrm{n}}$ of the copolymer linearly increases with conversion; the higher the fraction of acetal, the narrower the MWD [141]. The copolymer degrades in $5 \%$ alkaline medium at room temperature for $1 \mathrm{~h}$ to a degree of polymerization of $\sim 3$. Similar data were reported for the binary copolymerization of oligo(ethylene glycol methacrylate) with 2-methylene-4-phenyl-1,3-dioxolane, 5,6-benzo-2-methylene-1,3-dioxepane, or 2-methylene-1,3-dioxepane [140, 142]. Both copolymers and their degradation products were nontoxic.

The hydrolytic degradation of dioxolane copolymers with MMA (dioxolane-co-MMA) and oligo(ethylene glycol methacrylate) (dioxolane-coOEGMA) was studied in detail in comparison with the known biodegradable polymers, polylactide (PL), polycaprolactone (PCL), and the copolymer of lactide with glycolide (poly(lactide-co-glycolide), PLG) [134]. The rate of hydrolysis in the phosphate buffer

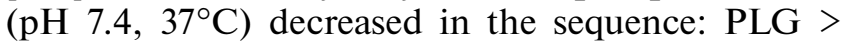
$\mathrm{PL}>$ dioxolane-co-OEGMA $>$ PCL $>$ dioxolane-coMMA.

The molecular weight of PLG decreased by $90 \%$ after one month; in the case of dioxolane-co-MMA, it decreased by $15-20 \%$ only after one year. Copolymers dioxolane-MMA were resistant to biodegradation like PMMA and oligo(ethylene glycol methacrylate), and the degree of enzymatic degradation of dioxolane-coOEGMA induced by Candida Antarctica was $13-15 \%$ for one week.

The developed approach, the controlled synthesis of degradable copolymers in the presence of ketene acetals, is also applicable to ternary copolymers [143]. For example, terpolymers MMA-AN-2-methylene4-phenyl-1,3-dioxolane and oligo(ethylene glycol methacrylate)-AN-2-methylene-4-phenyl-1,3-dioxolane synthesized under the same conditions and containing $40-70 \mathrm{~mol} \%$ dioxolane easily hydrolyze in an alkaline medium.

Another approach to the controlled synthesis of degradable polymer which includes the nitroxidemediated grafting polymerization of vinyl monomers onto various polysaccharides (cellulose, chitosan, starch) was briefly reviewed in 2021 [144]. The products of this synthesis cannot be treated as degradable, because only a polysaccharide part degrades.

\section{POLYNITROXIDES AS CATALYSTS}

To conclude, we will present several examples of catalysis with participation of polymeric nitroxides based on easily accessible TEMPO. These examples are not directly related to nitroxide-mediated polym- erization but are important from the point of view of the 9 th principle of green chemistry.

It is well known that nitroxides show catalytic activity in the oxidation of alcohols to aldehydes, ketones, and acids [145]. The main drawback of this process is the need to purify products from stable radicals. To circumvent this drawback polymers containing nitroxide radicals in side groups (polymeric nitroxides) are used [146]

The first attempt to use such a polymeric nitroxide, PS with side TEMPO radicals, instead of low molecular weight 4-methoxy-TEMPO for the oxidation of benzyl alcohol failed [147]. The yield of benzaldehyde was not above $50 \%$ compared with $100 \%$ attained in the presence of 4-methoxy-TEMPO. However, the oxidation process was very successful with the product of oxidation of the commercially available oligomer Chimassorb 944 [148]:

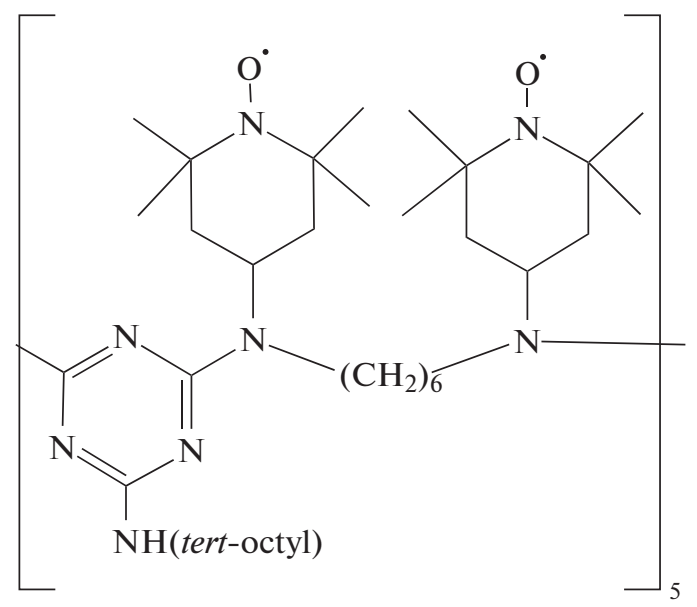

The yield of aldehydes and ketones in the oxidation of 12 alcohols with sodium hypochlorite in the presence of this oligomer was close to quantitative.

An efficient heterogeneous catalyst of oxidation of benzaldehyde to benzoic acid and cellulose to poly(uronic acid) with sodium hypochlorite was the polymer of 4-oxyvinyl-TEMPO [149]:

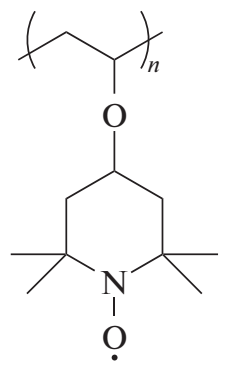

As catalysts of the aerobic oxidation of benzyl alcohol the authors of $[150,151]$ used newly synthesized poly(ether ketones) and polyamides functionalized by TEMPO 


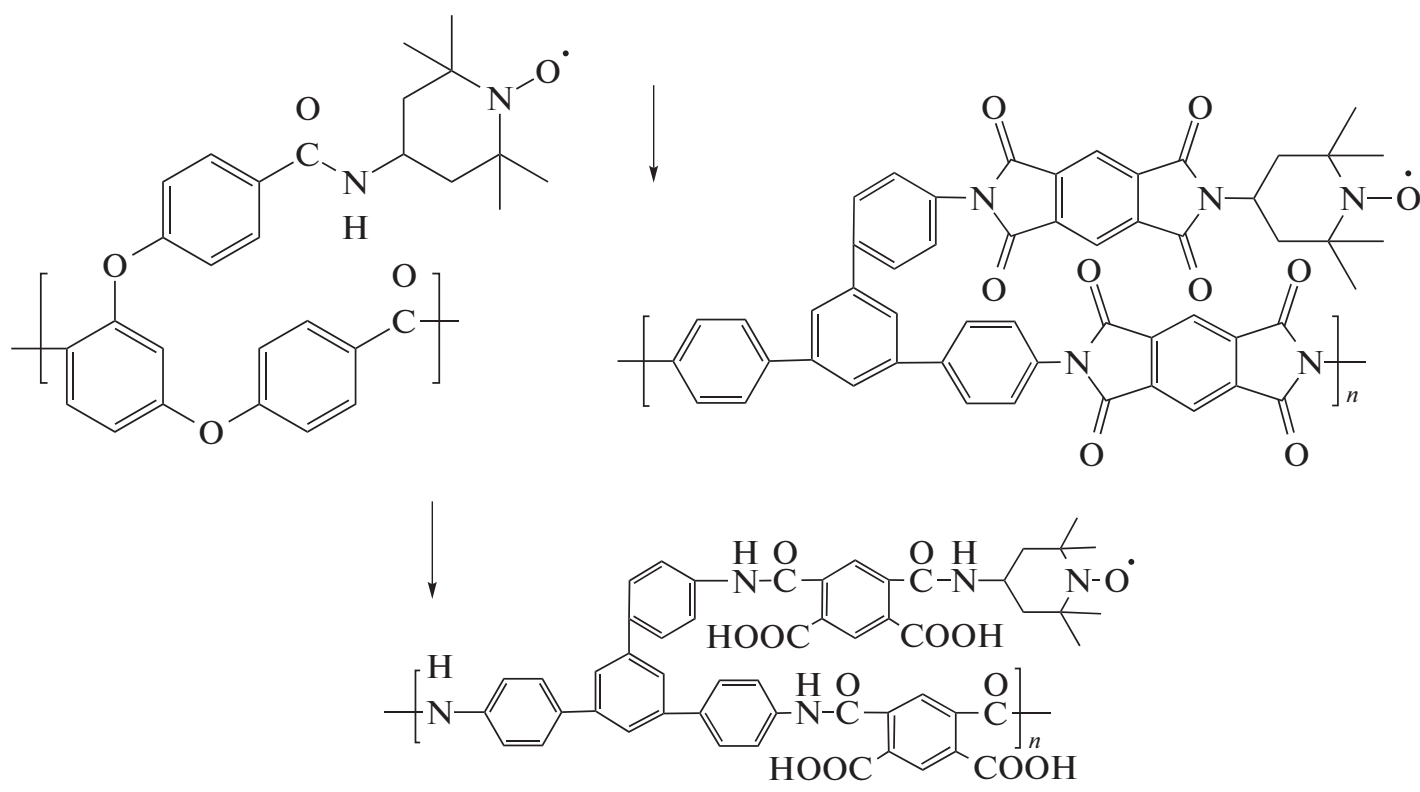

After six recycles the activity of the catalysts was $80-100 \%$.

The special study of PS and polyurethane with TEMPO side radicals as catalysts in the oxidation of various alcohols using sodium hypochlorite and bis(acetoxy)iodo benzene as co-oxidants demonstrated that the polymer nature has no effect on the catalytic activity of nitroxide [152]. No "polymer effect," that is, no increase in the activity of the catalyst owing to the concentration of catalytic sites on a macromolecule, was described in all the cited publications.

\section{CONCLUSIONS}

The controlled synthesis of polymers by the nitroxide-mediated reversible inhibition method was actively developed for almost three decades. This direction became not only the "versatile lab tool" of synthetic chemists making it possible to synthesize polymers with desired properties but it went on "industrial rails." The application of this method in the manufacture of adhesives, coatings, dispersers, and compatibilizers is expanding [94]. Therefore, the problems of green chemistry are very urgent and important for the specified processes, although special attention has been given to them only in the last decade.

This review covers only some, in our opinion, most urgent and promising ways to solve the issues of green chemistry in nitroxide-mediated reversible inhibition processes. The analysis of the published data shows that, in the field of dispersion polymerization in $\mathrm{scCO}_{2}$, encouraging results have been obtained for the controlled synthesis of polymers. In nitroxide-mediated photopolymerization, the desired degree of control has not yet been reached despite a considerable amount of publications in this area. Studies on the nitroxide-mediated controlled synthesis of polymers from renewable raw materials and easily degradable polymers are very few in number. Only few examples of these objects are available. However, first results demonstrate that these directions are promising. Just they, in our opinion, will deserve major attention from researchers in the nearest future.

\section{FUNDING}

This work was carried out within the project Modern Problems of Chemistry and Physical Chemistry of Macromolecular Compounds (State Assignment no. AAAA-A21121011990022-4).

\section{REFERENCES}

1. P. T. Anastas and J. C. Warner, Green Chemistry: Theory and Practice (Oxford Univ. Press, New York, 1998).

2. P. T. Anastas and J. B. Zimmerman, Environ. Sci. Technol. 37 (5), 95 (2003).

3. Green Chemistry: Fundamentals and Applications, Ed. by S. C. Ameta and R. Ameta (Apple Acad. Press; CRC Press; a Taylor and Francis, New York, 2013), Chap. 3.

4. R. A. Sheldon, Green Chem. 9, 1273 (2007).

5. M. A. Dube and S. Salehpour, Macromol. React. Eng. 8, 7 (2014).

6. R. A. Sheldon, ACS Sustainable Chem. Eng. 6, 32 (2018).

7. B. M. Trost, Science 254, 1471 (1991).

8. K. Matyjaszewski, Adv. Mater. 30, 1706441 (2018).

9. M. Destarac, Macromol. React. Eng. 4, 165 (2010).

10. D. F. Grishin and I. D. Grishin, Russ. J. Appl. Chem. 84, 2021 (2011).

11. C. Boyer, V. Bulmus, T. P. Davis, V. Ladmiral, J. Liu, and S. Perrier, Chem. Rev. 109, 5402 (2009). 
12. I. V. Ivanov, T. K. Meleshko, A. V. Kashina, and A. V. Yakimansky, Russ. Chem. Rev. 88, 1248 (2019).

13. A. M. Stolin, A. G. Merzhanov, and A. Ya. Malkin, Polym. Eng. Sci. 19, 1065 (1979).

14. M. Goikoetxea, R. Heijungs, M. J. Barandiaran, and J. M. Asua, Macromol. React. Eng. 2, 90 (2008).

15. A. Gandini, Macromolecules 41, 9491 (2008).

16. D. Y. Sogah, W. R. Hertler, O. W. Webster, and G. M. Cohen, Macromolecules 20, 1473 (1987).

17. K. L. Robinson, M. A. Khan, M. V. D. Banez, X. S. Wang, and S. P. Armes, Macromolecules 34, 3155 (2001).

18. R. A. Sheldon, Chem. Commun. 29, 3352 (2008).

19. T. G. Ribelli, F. Lorandi, M. Fantin, and K. Matyjaszewski, Macromol. Rapid Commun. 40, 1800616 (2019).

20. W. Kaminsky, Macromolecules 45, 3289 (2012).

21. R. Song, M. Murphy, C. Li, K. Ting, C. Soo, and Z. Zheng, Drug Des., Dev. Ther. 12, 3117 (2018).

22. M. Čolnik, M. K. Hrnčič, M. Škerget, and Ž. Knez, Chem. Ind. Chem. Eng. Q. 26, 401 (2020).

23. A. L. Roes and M. K. Patel, Risk Anal 27, 1311 (2007).

24. N. V. Tsarevsky and K. Matyjaszewski, Chem. Rev. 107, 2270 (2007).

25. C. Lu, C. Wang, J. Yu, J. Wang, and F. Chu, Green Chem. 16, 1854 (2014).

26. K. Surmacz and P. Chmielarz, Materials 13, 1717 (2020).

27. N. E. Achi, Y. Bakkour, W. Adhami, J. Molina, M. Penhoat, N. Azaroual, L. Chausset-Boissarie, and C. Rolando, Front. Chem. 8, 740 (2020).

28. X. Hu, N. Zhu, and K. Guo, Adv. Polym. Technol. 2019, Article ID 7971683 (2019).

29. S. Dadashi-Silab and K. Matyjaszewski, Molecules 25, 1648 (2020).

30. M. Jablonský, A. Škulcová, and J. Šima, Molecules 24, 3978 (2019).

31. J. Phommalysack-Lovan, Y. Chu, C. Boyer, and J. Xu, Chem. Commun. 54, 6591 (2018).

32. B. L. Buss and G. M. Miyake, Chem. Mater. 30, 3931 (2018).

33. M. Semsarilar and S. Perrier, Nat. Chem. 2, 811 (2010).

34. J. B. Mitchell, A. Samuni, M. C. Krishna, W. DeGraff, M. S. Ahn, and U. Samuni, Biochemistry 29, 2802 (1990)

35. K. Chen, J. F. Glockner, P. D. Morse, and H. M. Swartz, Biochemistry 28, 2496 (1989).

36. J. Glebska, J. Skolimowski, Z. Kudzin, K. Gwozdzinski, A. Grzelak, and G. Bartosz, Free Radicals Biol. Med. 35, 310 (2003).

37. J. Glebska and K. Gwozdzinski, Curr. Top. Biophys. 22, 75 (1998).

38. S. M. Hahn, C. M. Krishna, A. Samuni, W. DeGraff, D. O. Cuscela, P. Johnstone, and J. B. Mitchell, Cancer Res., Suppl. 54, 2006 (1994).

39. B. P. Soule, F. Hyodo, K.-I. Matsumoto, N. L. Simone, J. A. Cook, M. C. Krishna, and J. B. Mitchell, Antioxid. Redox. Signaling 9, 1731 (2007).
40. E. Zamir, R. L. Zhang, A. Samumi, M. Kogan, and J. Pe'er, Free Radicals Biol. Med. 27, 7 (1999).

41. M. Lewandowski and K. Gwozdzinski, Int. J. Mol. Sci. 18, 2490 (2017).

42. I. A. Kirilyuk, V. A. Svyatchenko, D. A. Morozov, E. I. Kazachinskaya, N. N. Kiselev, S. M. Bakunova, M. A. Voinov, V. B. Loktev, and I. A. Grigor'ev, Antibiot. Khimioter. 57, 3 (2012).

43. C. S. Winalski, S. Shortkroff, and R. V. Mulkern, Magn. Reson. Med. 48, 965 (2002).

44. J. F. W. Keana, S. Pow, and G. M. Rosen, Magn. Reson. Med. 3, 83 (1987).

45. G. Durand, F. Choteau, R. A. Prosak, A. Rockenbauer, F. A. Villamena, and B. Puccia, New J. Chem. 34, 1909 (2010).

46. X. Guo, J.-E. Seo, S. M. Bryce, J. A. Tan, Q. Wu, S. L. Dial, M. M. Moore, and N. Mei, Toxicol. Sci. 163, 214 (2018).

47. E. Guegain, J.-P. Michel, T. Boissenot, and J. Nicolas, Macromolecules 51, 724 (2018).

48. J. Nicolas, Y. Guillaneuf, C. Lefay, D. Bertin, D. Gigmes, and B. Charleux, Prog. Polym. Sci. 38, 63 (2013).

49. G. Moad amd E. Rizzardo, RSC Polym. Chem. Ser., No. 19, 1 (2016).

50. M. Yu. Zaremski, Polym. Sci., Ser. C 57, 65 (2015).

51. C. Detrembleur, C. Jerome, J. D. Winter, P. Gerbaux, J.-L. Clement, Y. Guillaneuf, and D. Gigmes, Polym. Chem. 5, 335 (2014).

52. Y. Guillaneuf, J.-P. Lamps, J.-M. Catala, D. Gigmes, and E. Drockenmuller, J. Polym. Sci., Part A: Polym Chem. 50, 3750 (2012).

53. J. Ruehl, N. L. Hill, E. D. Walter, G. Millhauser, and R. Braslau, Macromolecules 41, 1972 (2008).

54. C. M. R. Abreu, P. V. Mendonca, A. C. Serra, B. B. Noble, T. Guliashvili, J. Nicolas, M. L. Coote, and J. F. J. Coelho, Macromolecules 49, 490 (2016).

55. E. Guegain, Y. Guillaneuf, and J. Nicolas, Macromol. Rapid Commun. 36, 1227 (2015).

56. M. Yu. Zaremski and V. V. Odintsova, Polym. Sci., Ser. C (2021) (in press).

57. J. C. Scaiano, T. J. Connolly, N. Mohta, and C. N. Pliva, Can. J. Chem. 75, 92 (1997).

58. Y. Guillaneuf, D. Bertin, D. Gigmes, D.-L. Versace, J. Laleveé, and J.-P. Fouassier, Macromolecules 43, 2204 (2010).

59. A. Goto, J. C. Scaiano, and L. Maretti, Photochem. Photobiol. Sci. 6, 833 (2007).

60. J. Su, X. Liu, M. Li, T. Zhang, and Y. Cui, Int. J. Polym. Sci. 2016, Article ID 6482050 (2016).

61. D.-L. Versace, J. Lalevée, J.-P. Fouassier, Y. Guillaneuf, D. Bertin, and D. Gigmes, Macromol. Rapid Commun. 31, 1383 (2010).

62. D.-L. Versace, Y. Guillaneuf, D. Bertin, J. P. Fouassier, J. Lalevée, and D. Gigmes, Org. Biomol. Chem. 9, 2892 (2011).

63. J. Bosson, Ph.D. Thesis (Aix-Marseille Univ., Marseille, 2015).

64. J. Morris, S. Telitel, K. E. Fairfull-Smith, S. E. Bottle, J. Lalevée, J.-L. Clement, Y. Guillaneuf, and D. Gigmes, Polym. Chem. 6, 754 (2015). 
65. J. Su, X. Liu, J. Hu, Q. You, Y. Cui, and Y. Chen, Polym. Int. 64, 867 (2015).

66. A. Lin, Ph.D. Thesis (Aix-Marseille Univ., Marseille, 2019).

67. J. C. Morris, Ph.D. Thesis (Aix-Marseille Univ., Marseille, 2016).

68. D. R. Anderson, J. S. Keute, H. L. Chapel, and T. H. Koch, J. Am. Chem. Soc. 101, 1904 (1979).

69. S. E. Bottle, U. Chand, and A. S. Micallef, Chem. Lett. 26, 857 (1997).

70. A. D. Kalugina and M. Y. Mel'nikov, High Energy Chem. 41, 385 (2007).

71. J. F. W. Keana, R. Dinerstein, and T. Fredhelbmai, J. Org. Chem. 36, 118 (1971).

72. X. Liu, Y. Jing, and Y. Bai, Front. Chem. China 3, 41 (2008).

73. E. Yoshida, Polymers 4, 1125 (2012).

74. E. Yoshida, Colloid Polym. Sci. 287, 767 (2009).

75. E. Yoshida, Open J. Polym. Chem. 4, 47 (2014).

76. E. Yoshida, Colloid Polym. Sci. 288, 341 (2010).

77. E. Yoshida, Colloid Polym. Sci. 288, 239 (2010).

78. E. Yoshida, Colloid Polym. Sci. 288, 1639 (2010).

79. E. Yoshida, Colloid Polym. Sci. 287, 1417 (2009).

80. E. Yoshida, Colloid Polym. Sci. 289, 1625 (2011).

81. E. Yoshida, Polymers 4, 1580 (2012).

82. E. Yoshida, Colloid Polym. Sci. 288, 7 (2010).

83. S. Telitel, S. Telitel, J. Bosson, J. Lalevee, J.-L. Clément, M. Godfroy, J.-L. Fillaut, H. Akdas-Kilig, Y. Guillaneuf, and D. Gigmes, Langmuir 31, 10026 (2015).

84. A. H. Bonardi, F. Dumur, D. Gigmes, Y. Y. Xu, and J. Lalevée, ACS Omega 5, 3043 (2020).

85. S. Telitel, J. Morris, Y. Guillaneuf, J.-L. Clément, F. Morlet-Savary, A. Spangenberg, J.-P. Malval, J. Lalevée, D. Gigmes, and O. Soppera, ACS Appl. Mater. Interfaces 12, 30779 (2020).

86. S. Telitel, S. Telitel, J. Bosson, A. Spangenberg, J. Lalevée, F. Morlet-Savary, J.-L. Clement, Y. Guillaneuf, D. Gigmes, and O. Soppera, Adv. Mater. Int. 1, 1400067 (2014).

87. M. Huix-Rotllant and N. Ferré, J. Phys. Chem. A 118, 4464 (2014).

88. B. Charleux and F. Ganachaud, Macromol. Eng. 1, 605 (2007).

89. P. B. Zetterlund, Polym. Chem. 2, 534 (2011).

90. P. B. Zetterlund and M. Okubo, Macromolecules 39, 8959 (2006).

91. P. B. Zetterlund, Y. Kagawa, and M. Okubo, Chem. Rev. 108, 3747 (2008).

92. P. B. Zetterlund, F. Aldabbagh, and M. Okubo, J. Polym. Sci., Part A: Polym. Chem. 47, 3711 (2009).

93. M. Save, Y. Guillaneuf, and R. G. Gilbert, Aust. J. Chem. 59, 693 (2006).

94. E. Vivaldo-Lima, G. Jaramillo-Soto, and A. Penlidis, Encyclopedia of Polymer Science and Technology (John Wiley \& Sons, Inc., New York, 2016).

95. P. B. Zetterlund, S. C. Thickett, S. Perrier, E. BourgeatLami, and M. Lansalot, Chem. Rev. 115, 9745 (2015).

96. M. F. Cunningham, Prog. Polym. Sci. 33, 365 (2008).
97. R. Span and W. Wagner, J. Phys. Chem. 25, 1509 (1996).

98. P. G. Odell and G. K. Hamer, US Patent No. 5552502 (1996).

99. P. G. Odell, H. Georges, and G. K. Hamer, EU Patent No. 0735051A1 (1996).

100. R. McHale, F. Aldabbagh, P. B. Zetterlund, and M. Okubo, Macromol. Chem. Phys. 208, 1813 (2007).

101. F. Aldabbagh, P. B. Zetterlund, and M. Okubo, Macromolecules 41, 2732 (2008).

102. F. Aldabbagh, P. B. Zetterlund, and M. Okubo, Eur. Polym. J. 44, 4037 (2008).

103. J. M. Petraitis, Master's Thesis (Univ. California Santa Cruz, Santa Cruz, 2017).

104. C. Magee, A. Earla, J. Petraitis, C. Higa, R. Braslau, P. B. Zetterlund, and F. Aldabbagh, Polym. Chem. 5, 5725 (2014).

105. P. O'Connor, P. B. Zetterlund, and F. Aldabbagh, Macromolecules 43, 914 (2010).

106. P. O'Connor, PhD Thesis (Natl. Univ. Ireland, Galway, 2012).

107. J. Ryan, F. Aldabbagh, P. B. Zetterlund, and M. Okubo, Polymer 46, 9769 (2005).

108. R. McHale, F. Aldabbagh, P. B. Zetterlund, H. Minami, and M. Okubo, Macromolecules 39, 6853 (2006).

109. R. McHale, F. Aldabbagh, P. B. Zetterlund, and M. Okubo, Macromol. Rapid Commun. 27, 1465 (2006).

110. B. Grignard, T. Phan, D. Bertin, D. Gigmes, C. Jérôme, and C. Detrembleur, Polym. Chem. 1, 837 (2010).

111. D. G. Ramirez-Wong, C. A. Posada-Velez, E. SaldivarGuerra, J. G. Luna-Barcenas, C. Ott, U. S. Schubert, Macromol. Symp. 283-284, 120 (2009).

112. P. O'Connor, P. B. Zetterlund, and F. Aldabbagh, J. Polym. Sci., Part A: Polym. Chem. 49, 1719 (2011).

113. P. O’Connor, R. Yang, W. M. Carroll, Y. Rochev, and F. Aldabbagh, Eur. Poly. J. 48, 1279 (2012).

114. O. Garcria-Valdez, D. G. Ramrırez-Wong, E. Saldrıvar-Guerra, and J. G. Luna-Brarcenas J.G, Macromol. Chem. Phys. 214, 1396 (2013).

115. K. Satoh, Polym. J. 47, 527 (2015).

116. K. Yao and C. Tang, Macromolecules 46, 1689 (2013).

117. P. A. Wilbon, F. Chu, and C. Tang, Macromol. Rapid Commun. 34, 8 (2013).

118. Z. Szablan, A. A. Toy, T. P. Davis, X. Hao, M. H. Stenzel, and C. Barner-Kowollik, J. Polym. Sci., Part A: Polym. Chem. 42, 2432 (2004).

119. Z. Szablan, A. A. Toy, A. Terrenoire, T. P. Davis, M. H. Stenzel, A. H. E. Müller, and C. Barner-Kowollik, J. Polym. Sci., Part A: Polym. Chem. 44, 3692 (2006).

120. V. Anand, S. Agarwal, A. Greiner, and V. Choudhary, Polym. Int. 54, 823 (2005).

121. M. A. R. Meier, J. O. Metzger, and U. S. Schubert, Chem. Soc. Rev. 36, 1788 (2007).

122. S. Noppalit, A. Simula, L. Billon, and J. M. Asua, Polym. Chem. 11, 1151 (2020).

123. S. Tajbakhsh, F. Hajiali, and M. Marić, Ind. Eng. Chem. Res. 59, 8921 (2020). 
124. S. Tajbakhsh, F. Hajiali, and M. Marić, J. Appl. Polym. Sci. 138, e50095 (2021).

125. S. Tajbakhsh and M. Marić, J. Polym. Sci. (2021) (in press).

126. A. Métafiot, Y. Kanawati, J.-F. Gérard, B. Defoort, and M. Marić, Macromolecules 50, 3101 (2017).

127. A. Métafiot, L. Gagnon, S. Pruvost, P. Hubert, J.-F. Gérard, B. Defoort, and M. Marić, RSC Adv. 9, 3377 (2019).

128. A. Métafiot, PhD Thesis (INSA, Lyon, 2019).

129. P. Sarkar and A. K. Bhowmick, RSC Adv. 4, 61343 (2014).

130. S. B. Luk and M. Milan, Macromol. React. Eng. 13, 1800080 (2019).

131. R. A. Gross and B. Kalra, Science 297, 803 (2002).

132. H. Tian, Z. Tang, X. Zhuang, X. Chen, and X. Jing, Prog. Polym. Sci. 37, 237 (2012).

133. V. Siracusa, P. Rocculi, S. Romani, and M. Rosa, Trends Food Sci. Technol. 19, 634 (2008).

134. V. Delplace and J. Nicolas, Nat. Chem. 7, 771 (2015).

135. F. Quan, A. Zhang, F. Cheng, L. Cui, J. Liu, and Y. Xia, Polymers 10, 758 (2018).

136. Y. Wei, E. J. Connors, X. Jia, and C. Wang, Chem. Mater. 8 (3), 604 (1996).

137. Y. Wei, E. J. Connors, X. Jia, and C. Wang, J. Polym. Sci., Part A: Polym. Chem. 36, 761 (1998).

138. X. Jia, M. Li, S. Han, C. Wang, and Y. Wei, Mater. Lett. 31, 137 (1997).

139. X. Jia, J. Wang, Y. Liu, Z. Jin, M. Li, and Y. Wei, Polym. Int. 49, 1496 (2000).
140. V. Delplace, E. Guegain, S. Harrisson, D. Gigmes, Y. Guillaneuf, and J. Nicolas, Chem. Commun. 51, 12847 (2015).

141. J. Tran, E. Guegain, N. Ibrahim, S. Harrisson, and J. Nicolas, Polym. Chem. 7, 4427 (2016).

142. V. M. Delplace, PhD Thesis (Paris-Sud L'universite, Paris, 2015).

143. V. Delplace, S. Harrisson, A. Tardy, D. Gigmes, Y. Guillaneuf, and J. Nicolas, Macromol. Rapid Commun. 35, 484 (2014).

144. H. R. Lamontagne and B. H. Lessard, ASC Appl. Polym. Mater. 2, 5327 (2020).

145. S. Wertz and A. Studer, Green Chem. 15, 3116 (2013).

146. K.-A. Hansen and J. P. Blinco, Polym. Chem. 9, 1479 (2018).

147. T. Miyazawa and T. Endo, J. Polym. Sci., Part A: Polym. Chem. 23, 2487 (1985).

148. A. Dijksman, I. W. C. E. Arends, and R. A. Sheldon, Chem. Commun. 2000, 271 (2000).

149. W. Waskitoaji, T. Suga, and H. Nishide, AIP Conf. Proc. 1169, 13 (2009).

150. Y. Shi, Y. Nabae, T. Hayakawa, and M. Kakimoto, RSC Adv. 5, 1923 (2015).

151. Y. Nabae, M. Mikuni, N. Takusari, T. Hayakawa, and M. Kakimoto, High Perform. Polym. 29, 646 (2017).

152. M. A. Subhani, M. Beigi, and P. Eilbracht, Adv. Synth. Catal. 350, 2903 (2008).

Translated by T. Soboleva 